This is the author's final, peer-reviewed manuscript as accepted for publication. The publisher-formatted version may be available through the publisher's web site or your institution's library.

\title{
Kinetics of the Thermal Degradation of Patulin in the Presence of Ascorbic Acid
}

S. Kokkinidou, J. D. Floros, and L. F. LaBorde

\section{How to cite this manuscript}

If you make reference to this version of the manuscript, use the following information:

Kokkinidou, S., Floros, J. D., Laborde, L. F. (2014). Kinetics of the thermal degradation of patulin in the presence of ascorbic acid. Retrieved from http://krex.ksu.edu

\section{Published Version Information}

Citation: Kokkinidou, S., Floros, J. D., Laborde, L. F. (2014). Kinetics of the thermal degradation of patulin in the presence of ascorbic acid. Journal of Food Science, 79(1), T108-T114.

Copyright: (@ 2013 Institute of Food Technologists

Digital Object Identifier (DOI): 10.1111/1750-3841.12316

Publisher's Link: http://onlinelibrary.wiley.com/doi/10.1111/1750-3841.12316/abstract

This item was retrieved from the K-State Research Exchange (K-REx), the institutional repository of Kansas State University. K-REx is available at http://krex.ksu.edu 
Kinetics of the Thermal Degradation of Patulin in the Presence of Ascorbic Acid

$$
\text { Kokkinidou S. }{ }^{1} \text {, } \text {, Floros J.D. }{ }^{2} \text {, LaBorde L.F. }{ }^{3}
$$

${ }^{1}$ Present Address: Department of Food Science and Nutrition, University of Minnesota, St. Paul, MN 55108, USA.

Previous Address: Department of Food Science, The Pennsylvania State University, University Park, PA 16802, USA

${ }^{2}$ Present Address: College of Agriculture, Kansas State University, Manhattan, KS 66506, USA.

Previous Address: Department of Food Science, The Pennsylvania State University, University Park, PA 16802, USA

${ }^{3}$ Department of Food Science, The Pennsylvania State University, University Park, PA 16802, USA.

* Corresponding author

\section{Word Count: 4,942}

Patulin Thermal Degradation Kinetics (...)

Submission to JFS Toxicology and Chemical Food Safety 


\begin{abstract}
Degradation of the mycotoxin patulin between $25-85{ }^{\circ} \mathrm{C}$ without and with added ascorbic acid was studied, and the usefulness of linear and non-linear models for predicting reaction rates was compared. In agreement with previous reports, ascorbic acid significantly increased $(\mathrm{p} \leq 0.05)$ the rate of patulin degradation at all temperatures studied. The data for patulin degradation in the absence of ascorbic acid were adequately modeled using a zero-order linear kinetic model. However, the predictive abilities of zero and higher order linear models were not adequate to describe the more complex reactions that likely occurred when ascorbic acid was added. In contrast, the non-linear Weibull model adequately described the patulin-ascorbic acid reaction throughout the temperature range studied. Zero-order rate constants and Weibull scale values for each of the respective reactions followed the Arrhenius law. Activation energies of $58.7 \pm 3.9$ and $29.6 \pm 1.9 \mathrm{~kJ}$ $\mathrm{mol}^{-1}$ for the reaction without and with ascorbic acid, respectively, confirmed decreased patulin stability in the presence of ascorbic acid and suggested that the mechanisms for the two degradation reactions were different.
\end{abstract}

Keywords: Patulin, Ascorbic acid, Kinetics, Thermal degradation, Weibull model.

\title{
Practical application
}

Ascorbic acid is known to increase the rate of degradation of patulin in apple juice. Because this vitamin is Generally Recognized As Safe (GRAS), inexpensive, recognized by consumers as a beneficial nutrient, and does not negatively affect the sensory properties of apple juice, it may find application for reducing levels of this mycotoxin. 
Kinetic studies on the reaction of ascorbic acid and patulin are useful for providing information about the reaction mechanism and for process optimization studies to determine thermal processing schemes and post processing storage conditions that can be used to minimize patulin levels in apple juice.

\section{Introduction}

Patulin is a mycotoxin produced by several mold genera including Penicillium, Aspergillus and Byssochlamys. P.expansum, a common cause of post-harvest decay of apples, is the most common source of patulin contamination in apples and processed apple products (Paster and others 1995).Animal and cell studies have demonstrated a variety of acute and chronic effects exerted by patulin including neurotoxicity, immunotoxicity, carcinogenicity, teratogenicity, and mutagenicity (Alves and others 2000; Escoula and others 1988; Geiber and Conn 1945; Mayer and Legator 1969; Paucod 1990; Sharma 1993; Taniwaki 1992). Although only indirect evidence suggests that patulin is harmful to humans, data from animal toxicological studies and human consumption rates have been used by international food regulatory agencies to establish maximum allowable levels. In the U.S., the Food and Drug Association (FDA) has established an action level for patulin in single strength apple juice of $50 \mu \mathrm{g} / \mathrm{kg}(50 \mathrm{ppb})$ (FDA 2001) and requires that patulin control measures be included in FDA mandated Juice Hazards Analysis Critical Control Point (HACCP) plans (FDA 2004).In other countries, maximum allowable levels as low as $25 \mu \mathrm{g} / \mathrm{kg}$ have been mandated (FAO 2002). 
Post harvest methods for minimizing patulin levels in apple juice include the use of fungicides, bio control agents, and controlled atmospheric storage to inhibit mold growth (Morales and others 2010)FDA recommendations are to purchase only sound, tree picked apples, and to use culling, trimming and washing methods to remove decayed apple tissue. However, these methods may not be reliable since patulin may diffuse into apple tissues where decay is not apparent during visual inspection(Beretta 2010).

A comprehensive review of factors affecting patulin stability in apple products was conducted by (Moake and others 2005). Although degradation is more rapid at higher $\mathrm{pH}$ values (Drusch and others 2007), patulin is relatively stable during heat processing in acidic apple juice. Addition of sulfite, sulfur dioxide, cysteine, and glutathione have been shown to reduce patulin levels during processing and storage (Ciegler and others 1976; Fliege and Metzler 2000a, 2000b). Of particular interest are studies that have demonstrated accelerated degradation of patulin in the presence of ascorbic acid (Alves and others 2000; Aytac and Acar 1994; Canas and Aranda 1996; Drusch and others 2007; Fremy and others 1995). Ascorbic acid is Generally Recognized As Safe (GRAS) when used in accordance with Good Manufacturing Practices (21CFR $182.3013,2000$ ), is relatively inexpensive, and is widely recognized by consumers as a beneficial nutrient (vitamin C).There is some evidence that patulin reductions are accompanied by a decrease in genotoxicity (Alves and others 2000). Thus, the use of ascorbic acid shows promise as a method for controlling the hazards presented by this mycotoxin. Although the effectiveness of ascorbic acid has been shown repeatedly, there have been no controlled kinetic studies conducted that could provide insight on the reaction mechanism. 
The most common approach for modeling microbial lethality or chemical degradation in foods has been to use zero, first, or second-order kinetic models (Villota and Hawkes 2007). However for complex reactions, the rate at any time, determined by applying linear regression, may be over- or under-estimated depending on how well the model fits the experimental data. In order to overcome these limitations, the more flexible non-linear Weibull model has been used to incorporate parameters for both curve shape and rate (Corradini and Peleg 2004). The Weibull model has found useful application for modeling inactivation of microorganisms (Chen and Hoover 2004; Huang 2009; Keklik and others 2012; Van Boekel 2002) as well as degradation of nutrients, pigments and enzymes during food processing and storage (Corradini and Peleg 2004; Mafart and others 2002; Manso and others 2001; Odriozola-Serrano and others 2009; Oms-Oliu and others 2009; Tiwari and others 2009; Zheng and Lu 2011).

Accurate prediction of degradation reaction rates in foods may require different mathematical models depending on the compound studied. Odriozola-Serrano and others (2009) reported that a Weibull kinetic model most accurately estimated changes in anthocyanins and antioxidant capacity of fresh-cut strawberries during storage, although a first-order model was adequate for predicting loss of vitamin C. Zheng and Lu (2011) determined that the first-order kinetic model was adequate for predicting reductions of ascorbic acid and total phenols during pasteurization of pineapple juice. However, in the same juice samples, the Weibull model more accurately predicted changes in radical scavenging activity.

An understanding of the kinetics of the degradation of patulin in the presence of ascorbic acid is necessary to further explore the usefulness of this approach for 
controlling mycotoxin levels in apple juice. The objective of this study is therefore to use statistical methods to compare the ability of linear models and the non-linear Weibull model for predicting the degradation of patulin without or with ascorbic acid added.

\section{Materials and Methods}

\section{Chemicals}

Patulin ( $\geq 98 \%$ pure, crystalline), ascorbic acid, and malic acid were obtained from Sigma Aldrich, (St. Louis, Mo., U.S.A). Acetonitrile (HPLC grade), water (HPLC grade), and formic acid (reagent grade) used for High Performance Liquid Chromatography (HPLC) analysis were obtained from Fisher Scientific (Fair Lawn, N.J., U.S.A).

\section{Reaction medium}

Experiments were conducted using an apple juice model system consisting of $0.5 \%$ malic acid adjusted to $\mathrm{pH} 3.75$. Values for malic acid concentration and $\mathrm{pH}$ were based on typical levels reported in apple juice (Mattick and Moyer 1983).The concentration of ascorbic acid chosen is based on the range of recommend daily intake values for single serving of juice. Addition of $\mathrm{NaOH}(1 \mathrm{M})$ solution was used to vary $\mathrm{pH}$ and measurements were performed using an Accumet AR25 dual channel pH/ion meter (Fisher Scientific, Fair Lawn, N.J., U.S.A).

\section{Sample preparation and treatment}

Stock solutions of patulin were prepared according to AOAC procedures (MacDonald and others 2000). Five (5.00) $\mathrm{mg}$ of patulin was dissolved in $5 \mathrm{~mL}$ of ethyl 
acetate in a $25-\mathrm{ml}$ volumetric flask, brought to volume with ethyl acetate, and stored at $20^{\circ} \mathrm{C}$ until used. To prepare reaction solutions, the stock solution was warmed to room temperature, $1.0 \mathrm{~mL}$ was transferred to a test tube, and the contents were dried under $\mathrm{N}_{2}$ gas. Immediately after drying, $4.0 \mathrm{ml}$ of distilled water acidified to $\mathrm{pH} 4.0$ with acetic acid was added and the solution was vigorously vortexed for $30 \mathrm{sec}$. The aqueous solution containing approximately $50,000 \mathrm{ppb}$ patulin was kept at $4^{\circ} \mathrm{C}$ until use. Before each experiment, the actual concentration of patulin was determined by HPLC.

Prior to each experiment, $0.5 \%$ malic acid buffer was added to a $250 \mathrm{ml}$ Erlenmeyer flask, which was then immersed in a temperature controlled recirculating water bath (NESLAB RTE-17, Thermo Scientific, Waltham, Mass., U.S.A) for 30 min to allow for temperature equilibration. The water bath temperature was monitored using a digital thermocouple and was maintained to a precision of $\pm 0.5^{\circ} \mathrm{C}$. The thermocouple was checked against a certified reference thermometer that was calibrated annually by an NIST laboratory. The level of water was maintained at least 1.5 inches above the reaction solution level in the flask to ensure uniform temperature distribution. The flask was then removed from the water bath and appropriate amounts of patulin stock solution and ascorbic acid were added to achieve a final volume of $50 \mathrm{ml}$ and respective concentrations of $6.40 \mu \mathrm{M}(1000 \mathrm{ppb})$ and $1.25 \mathrm{mM}(221 \mathrm{ppm})$. The mixture was mechanically stirred for $20 \mathrm{sec}$ with a stir bar after which the flask was immediately returned to the water bath. The change in volume caused by addition of reactants did not change the reaction solution volume by more than $2 \%$. At each reaction time interval, 1.0 $\mathrm{mL}$ of sample was taken from the reaction vessel for HPLC patulin analysis and the flask was immediately returned to the water bath. The range of temperatures $\left(25-85^{\circ} \mathrm{C}\right)$ for 
experiments was chosen to simulate conditions that may occur during thermal processing and post processing storage of shelf stable juice. Each reaction was followed until patulin was below the detection limit or when no further significant changes in concentration occurred.

\section{Patulin analysis}

Patulin was quantified using a Waters HPLC system (pump model: 600; Autosampler: 71P; photodiode array (PDA) detector: 2998, Waters Inc., Milford, Mass., U.S.A.) and a C-18 reverse phase/cation exchange column (Primesep-D, $4.6 \mathrm{~mm} \times 150$ mm, particle size $5 \mu \mathrm{m}$, SIELC Inc., Prospects Heights, Ill., U.S.A.). A two-solvent gradient elution system was used. Solvent A consisted of water containing $0.1 \%$ formic acid adjusted to $\mathrm{pH} 1.85$ with HCL. Solvent B was acetonitrile. Gradient conditions (v/v) were as follows: $98 \% \mathrm{~A}: 2 \% \mathrm{~B}$ at $0 \mathrm{~min}, 95 \% \mathrm{~A}: 5 \% \mathrm{~B}$ at $3 \mathrm{~min} ; 90 \% \mathrm{~A}: 10 \% \mathrm{~B}$ at $5 \mathrm{~min}$, $85 \%$ A: $15 \% \mathrm{~B}$ at $7 \mathrm{~min}$. The flow rate was maintained at $1 \mathrm{~mL} / \mathrm{min}$. At each reaction time interval, $20 \mu \mathrm{L}$ was injected directly onto the column without prior extraction or clean up. The identity of patulin was confirmed by comparing retention times and maximum absorbance wavelength (4.4 min and $276.0 \mathrm{~nm}$, respectively). Standard curves for patulin were prepared by plotting the concentration of prepared aqueous solutions vs. peak area at $A_{\max }$. The detection limit for patulin was $0.165 \mu \mathrm{M}(25 \mathrm{ppb})$.

\section{Kinetic models}

Patulin degradation was modeled using the following zero-order (Eq. 1), firstorder (Eq. 2), and second-order (Eq. 3), equations:

$$
\begin{aligned}
& \mathrm{C}_{\mathrm{t}}=\mathrm{C}_{0}-\left(\mathrm{k}_{0} \cdot \mathrm{t}\right) \\
& \mathrm{C}_{\mathrm{t}}=\mathrm{C}_{0} \cdot \exp \left(-\mathrm{k}_{1} \cdot \mathrm{t}\right)
\end{aligned}
$$




$$
1 / \mathrm{C}_{\mathrm{t}}=1 / \mathrm{C}_{0}+\left(\mathrm{k}_{2} \cdot \mathrm{t}\right)
$$

Where $\mathrm{C}_{\mathrm{t}}$ and $\mathrm{C}_{0}$ are patulin concentrations, at time $\mathrm{t}$ and zero, respectively and $\mathrm{t}$ is the reaction time. $\mathrm{k}_{0}, \mathrm{k}_{1}$, and $\mathrm{k}_{2}$ are zero, first, and second-order rate constants, respectively.

The data were also used to fit the Weibull model from Corradini and Peleg (2004):

$$
\mathrm{C}_{\mathrm{t}} / \mathrm{C}_{0}=\exp \left(-\mathrm{b} \cdot \mathrm{t}^{\mathrm{n}}\right)
$$

Where $\mathrm{b}=$ the Weibull scale parameter $\left(\min ^{-n}\right)$ and $n=$ the shape parameter. The scale parameter (b) is analogous to a rate constant and as such is usually dependent on reaction temperature. The shape parameter (n) mathematically describes the shape of the degradation curve. When $n>1$, the degradation rate increases with time and when $n<1$, the rate decreases with time. When $n=1$, the equation is equivalent to a simple first-order kinetic model. The value for the shape parameter remains constant with increasing temperature if the reaction mechanism is unaffected by temperature.

\section{Temperature dependency}

The Arrhenius equation was used to compare the temperature dependency of patulin degradation according to the equation:

$$
\ln (\mathrm{k} \text { or } \mathrm{b})=-\mathrm{E}_{\mathrm{A}} / \mathrm{RT}+\ln \mathrm{A}
$$

where $\mathrm{k}=$ the rate constant for the reaction, $\mathrm{b}=$ the Weibull scale parameter, $\mathrm{Ea}=$

activation energy $\left(\mathrm{J} \mathrm{mol}^{-1}\right), \mathrm{R}=$ the gas constant $\left(8.314 \mathrm{~J} \mathrm{~mol}^{-1} \mathrm{~K}^{-1}\right), \mathrm{T}=$ Temperature $\left({ }^{\mathrm{O}} \mathrm{K}\right)$, and $\mathrm{A}=$ the Arrhenius pre exponential factor.

\section{Statistical analysis}

Experiments for each treatment and temperature were conducted in triplicate. SAS statistical software (Release 9.1.3 SAS institute Inc, Carry, NC, U.S.A.) and 
GraphPad Prism (Version 5.0d GraphPad Software Inc.) were used for 2-way ANOVA determination of the significance of reaction parameters, and to determine apparent zero, first, and second-order rate constants, Weibull scale (b) and shape (n) factors, and the goodness of fit of the experimental data to each model. Regression coefficients $\left(\mathrm{R}^{2}\right)$ described the percentage of variability within the data explained by the model. The standard deviation for residuals (Sy.x) was used to measure how close the data were to the fitted regression line. Residual plots as a function of reaction time were presented as graphical inserts within each figure. For each model, Wald-Wolfowitz tests, known as the Runs test for randomness, were used to test the null hypothesis that there is no systematic deviation from the curve generated by the model. A p-value less than or equal to 0.05 indicates a non-random distribution of residuals and thus a significant deviation from the model.

\section{Results and Discussion}

Data for the degradation of patulin without and with ascorbic acid added were followed for up to 148 hours. Decreases in patulin concentration were significantly $(\mathrm{p}<0.001)$ affected by reaction temperature and the presence of added ascorbic acid. These results are in agreement with earlier studies on factors affecting patulin degradation in model systems and processed juice ((Alves and others 2000; Aytac and Acar 1994; Canas and Aranda 1996; Drusch and others 2007; Fremy and others 1995).

\section{Patulin degradation without added ascorbic acid}

Data for the degradation of patulin $\left(\mathrm{C}_{0}=6.40 \mu \mathrm{M}\right)$ at $25,35,45,55,65$, and $85^{\circ} \mathrm{C}$ in samples with no added ascorbic acid and fitted with a zero-order kinetic model are 
presented in Figure 1. Inserted in this figure, and in subsequent figures, is a residual plot for the reaction at $45^{\circ} \mathrm{C}$. Residual plots at this temperature were representative of trends that occurred at all temperatures studied for each of the models evaluated for reactions without or with ascorbic acid. In Table 1, rate constants and statistical results to evaluate the fit of the zero-order model to the experimental data are shown.

The apparent random distribution of residuals with reaction time (Figure 1) confirms goodness of fit for the zero-order model. The fit of the zero-order model to data obtained at all reaction temperatures was high as evidenced by $\mathrm{R}^{2}$ values of at least 0.959 and consistently low Sy.x values at each temperature (Table 1). Generated p-values by runs tests were well above 0.05 for all temperatures, indicating that deviations from the zero order kinetic model were not statistically significant. When fits of first and secondorder models to the experimental data were compared to the zero-order model, no meaningful increases in $\mathrm{R}^{2}$ values or decreases in $\mathrm{p}$ values occurred, thus indicating that no statistically significant deviations from each of the linear models occurred (data not shown). Therefore, the zero-order rate model, within these experimental conditions, can be used to predict the extent to which patulin degradation occurs when no ascorbic acid is added.

\section{Patulin degradation with added ascorbic acid}

In Figure 2a, b, and c, respective fits of a) zero, b) first, and c) second-order kinetic models are compared for the degradation of patulin with added ascorbic acid at 25, $35,45,55,65$, and $85^{\circ} \mathrm{C}$ respectively. In contrast to the good fit of the zero-order kinetic model to data obtained for patulin degradation when no ascorbic acid is added (Figure 1), it is visually apparent from Figure 2a that this model is not satisfactory. The residual plot 
insert presents a non-random distribution and shows a systematic underestimation of patulin degradation during the initial part of the reaction and overestimation at longer times indicating the poor fit of the model. As expected, zero-order rate constants $\left(\mathrm{k}_{0}\right)$ for patulin degradation when ascorbic acid is added (Table 2) were consistently higher compared to $\mathrm{k}_{0}$ values obtained when no ascorbic acid was added (Table 1). However, the fit of the zero-order model was poor as evidenced by $\mathrm{R}^{2}$ values between 0.663 and 0.858 and comparatively higher Sy.x values at each temperature. Runs test yielded p values were consistently less than 0.05 , thus indicating systematic deviation from the zero-order model occurred at all temperatures except $85^{\circ} \mathrm{C}$.

When the fit of first and second-order models to the data were compared (Figure 2b and 2c), there was little or no improvement compared to the zero-order model. Plots of the residuals at each reaction time again showed that predicted values underestimated and then overestimated experimental values as reaction time increased. Although changes in $\mathrm{k}_{1}$ and $\mathrm{k}_{2}$ values in Table 2 confirmed the positive effect of temperature on reaction rate, the statistical data show only moderate improvement in the predicative ability of the first and second-order kinetic model compared to the zero-order model. Respective $\mathrm{R}^{2}$ value ranges among the reaction temperatures increased from between 0.824 and 0.920 for the first-order model to 0.871 to 0.971 for the second-order model. Standard deviation values for the residuals (Sy.x) for both linear models tended to increase with increasing temperatures. Systematic deviation of the first-order model to the experimental data was significant $(\mathrm{p} \leq 0.05)$ for all reaction temperatures and deviation of the second-order model was significant at all temperatures except 35 and $85^{\circ} \mathrm{C}$. These results indicate that simple 
linear kinetic models are not adequate for predicting the extent to which patulin degradation occurs between 25 and $85{ }^{\circ} \mathrm{C}$ when added ascorbic acid is present.

In summary, thermal degradation of patulin in the absence of ascorbic acid between 25 and $85^{\circ} \mathrm{C}$ can be adequately described by a simple zero order kinetic model. However, it appears that addition of ascorbic acid increases the complexity of the degradation reaction and leads to inaccurate prediction of reaction rates when simple linear kinetic models are used.

\section{Weibull Model.}

Figure 3a illustrates the fit of the Weibull model to the data for degradation of patulin with added ascorbic acid within the same temperature range. In contrast to results for the linear models (Figure 2), it is visually apparent from the residual plot insert that the Weibull residuals are more randomly distributed. Values for the Weibull scale parameter (b) in Table 3 increased as the temperature was raised from 25 to $85^{\circ} \mathrm{C}$, which was expected given that the scale parameter is analogous to rate constant $(\mathrm{k})$ used in linear kinetic models. Shape parameter $(n)$ values did not significantly $(\mathrm{p}>0.05)$ differ

between 25 and $85^{\circ} \mathrm{C}(\bar{n}=0.453 \pm 0.033)$. All $\mathrm{R}^{2}$ values were very high $(0.987-0.999)$ with no apparent trend with respect to temperature. Sy.x values also changed little with temperature. Runs test p-values were well above 0.05 for each temperature indicating consistent goodness of fit of the Weibull model to the experimental data. These results show that the predictive ability of the non-linear Weibull model is superior to linear models for the degradation of patulin when ascorbic acid is added under the conditions present in this study. 
Because the shape parameter (n) was independent of temperature, it can be assumed that the reaction mechanism remains the same through the entire temperature range studied (Corradini \& Peleg, 2004). Thus, Equation 4 can be simplified by replacing the variable term $\mathrm{n}$ with the average value obtained within the temperature range studied to yield a simplified Weibull equation as follows:

$$
\mathrm{C} / \mathrm{Co}=\exp \left(-\mathrm{b} \cdot \mathrm{t}^{0.453}\right)
$$

The plot for the fit of the simplified Weibull model to the data and the residual plot insert in Figure 3b appears very similar to the full Weibull plot in Figure 3a. Analysis of the statistical data for simplified Weibull in Table 4 showed again that b values increase at higher temperatures, all $\mathrm{R}^{2}$ values remained very high (0.985 - 0.999), and Sy.x values were low with no apparent upward or downward trend with increasing temperature. There were no significant deviations of the fit of the simplified Weibull to the experimental data as evidenced by runs tests p-values well above 0.05 . Thus, the superior predictive ability of the Weibull model in Equation 4 is not negatively affected by simplification to Equation 6.

\section{Reaction temperature dependency.}

A comparison of temperature dependency for the degradation of patulin without and with ascorbic acid added is shown by in the Arrhenius plot in Figure 4. Based on the previous results in this study, zero-order rate constants were used to quantify patulin degradation rates in the absence of added ascorbic acid while simplified Weibull scale parameters (b) were used for the degradation of the patulin when ascorbic acid was added. The relationship between $\ln \left(\mathrm{k}_{0}\right)$ or $\ln (\mathrm{b})$ versus the inverse of the absolute reaction temperature $(1 / T)$ were highly linear $\left(R^{2}=0.985\right.$ and 0.987$)$, respectively, indicating an 
Arrhenius type temperature dependency for both reactions. Calculated activation energies for patulin degradation without and with added ascorbic acid were 58.7 and $29.6 \mathrm{kJmol}^{-1}$, respectively. Both values are in the range reported for other food chemical reactions (Villota and Hawkes 2007).The lower activation energy observed for the degradation of patulin in the presence of ascorbic acid is consistent with the accelerating effect of ascorbic acid reported in this and other studies, and suggests that the two reactions occur via different mechanisms.

From the kinetic data presented in this study, it can be hypothesized that, in the absence of ascorbic acid, patulin degradation occurs by a simple single-step reaction that is well predicted by the zero-order kinetic model. However, addition of ascorbic acid increases the complexity of the degradation reaction as evidenced by the poor fit of zero, first, and second-order linear models (Figure 2, Table 2).

Studies by Fliege and Metzier (2000a, 2000b) and Cielger and others (1976) provided evidence that the electrophilic properties of patulin make it a suitable target for nucleophilic attack via Michael addition with the resulting formation of stable adducts. Although these studies were limited to the effects of sulfhydryl compounds, it can be hypothesized that ascorbic acid, acting as a nucleophile, accelerates patulin degradation by a similar complex mechanism. Alternatively, oxidative degradation of ascorbic acid may form reactive free radicals that attack the lactone structure of patulin (Brackett and Marth 1979; Drusch and others 2007). It is possible that both degradation mechanisms occur, the predominance of either one depending on the relative amount of ascorbic acid and oxygen present in solution as the reaction proceeds. Further elucidation of the mechanistic pathway for this reaction can be achieved by LC/MS identification of 
intermediate and end products. Structural identification and conformation may then be achieved through NMR spectroscopy and isotopic carbon module labeling techniques. Isolation and purification of intermediate and final products should be followed by cellular and animal toxicity studies to determine if the disappearance of patulin when ascorbic acid is added is accompanied by detoxification.

\section{Conclusions}

The results of this study are in agreement with previous studies in model and juice systems showing that ascorbic acid increases the rate of patulin degradation. Although the zero-order kinetic model was adequate for describing the degradation of patulin in the absence of ascorbic acid, zero-order and higher linear models did not adequately describe the more complex reaction that occurs when ascorbic acid is present. In contrast, the Weibull model, and its simplified form, more accurately predicted patulin degradation when ascorbic acid was added, and therefore, may be useful for determining intrinsic and extrinsic factors affecting the destruction of patulin in the presence of ascorbic acid and to validate predictive models applicable to apple juice. The information gained could then be used to determine thermal processing schemes and post processing storage conditions to minimize patulin levels in apple juice containing added ascorbic acid. In this study, the reaction of patulin with ascorbic acid was studied in a model system. Therefore, further research is needed to validate the usefulness of the predictive models in apple juice within typical concentration ranges of chemical juice constituents and $\mathrm{pH}$ levels. The information gained could then be used to determine thermal processing schemes and 
post processing storage conditions to minimize patulin levels in apple juice containing added ascorbic acid. 


\section{References:}

21CFR 182.3013. 182.3013,2000. Code of Federal regulations, Section 182.3013 - Ascorbic acid Title 21 - Food and Drugs. PART 182 - SUBSTANCES GENERALLY RECOGNIZED AS SAFE. Subpart D - Chemical Preservatives.

Alves I, Oliveira NG, Laires A, Rodrigues AS, Rueff J. 2000. Induction of micronuclei and chromosomal aberrations by the mycotoxin patulin in mammalian cells: Role of ascorbic acid as a modulator of patulin clastogenicity. Mutagenesis 15:229-234.

Aytac SA, Acar J. 1994. Einflub von L-ascorbinsäure und schwefeldioxidzusatz auf die stabilität von patulin in apfeläften und pufferlösungen. Ernährung 1:15-17.

Beretta B. 2010. Patulin in apple-based foods : Occurrence and safety evaluation. Food Additives and Contaminants:37-41.

Brackett RE, Marth EH. 1979. Ascorbic acid and ascorbate cause disappearance of patulin from buffer solutions and apple juice. Journal of Food Protection 42:864-866.

Canas P, Aranda M. 1996. Decontamination and inhibition of patulin-induced cytotoxicity. Environmental Toxicology and Water Quality: An International Journal 11:249-253.

Chen H, Hoover DG. 2004. Use of Weibull model to describe and predict pressure inactivation of Listeria monocytogenes Scott A in whole milk. Innovative Food Science \& Emerging Technologies 5:269-276.

Corradini MG, Peleg M. 2004. A model of non-isothermal degradation of nutrients, pigments and enzymes. Journal of the Science of Food and Agriculture 84:217-226.

Drusch S, Kopka S, Kaeding J. 2007. Stability of patulin in a juice-like aqueous model system in the presence of ascorbic acid. Food Chemistry 100:192-197.

Escoula L, Thomsen M, Bourdiol D, Pipy B, Peuriere S, Roubinet F. 1988. Patulin immunotoxicology: Effect on phagocyte activation and the cellular and humoral immune system of mice and rabbits. International Journal of Immunopharmacology 10:983-989.

FDA. 2001. Compliance Policy Guide Sec. 510.150 Apple Juice, Apple Juice Concentrates, and Apple Juice Products - Adulteration with Patulin.

FDA. 2004. Guidance for Industry: Juice HACCP Hazards and Controls Guidance First Edition; Final Guidance. U.S. Department of Health and Human Services, Food and Drug Administration.

Fliege R, Metzler M. 2000a. Electrophilic properties of patulin. Adduct structures and reaction pathways with 4-bromothiophenol and other model nucleophiles. Chemical Research in Toxicology 13:363-72.

Fliege R, Metzler M. 2000b. Electrophilic properties of patulin. N-acetylcysteine and glutathione adducts. Chemical Research in Toxicology 13:373-81. 
Food and Agriculture Organization of the United Nations. Comments on the Draft Maximum Level for Patulin in Apple Juice and Apple Juice Ingredients in Other Beverages [Internet]. Codex Alimentarius Commission on Food Additives and Contaminants. Available from: ftp://ftp.fao.org/codex/meetings/CCFAC/CCFAC34/fa02 19e.pdf

Fremy JM, Castegnaro MJ, Gleizes E, De Meo M, Laget M. 1995. Procedures for the destruction of patulin in laboratory wastes. Food Additives and Contaminants 12:331-336.

Geiber WB, Conn JE. 1945. The mechanism of the antibiotic action of clavacin and penicillic acid. Journal of American Chemical Society 67:112-115.

Huang L. 2009. Thermal inactivation of Listeria monocytogenes in ground beef under isothermal and dynamic temperature conditions. Journal of Food Engineering 90:380-387.

Keklik NM, Demirci A, Puri VM, Heinemann PH. 2012. Modeling the inactivation of Salmonella Typhimurium, Listeria monocytogenes, and Salmonella Enteritidis on poultry products exposed to pulsed UV light. Journal of Food Protection 75:281-8.

MacDonald S, Long M, Gilbert J, Felgueiras I. 2000. Liquid chromatographic method for determination of patulin in clear and cloudy apple juices and apple puree: collaborative study. Journal of AOAC International 83:1387-94.

Mafart P, Couvert O, Gaillard S, Leguerinel I. 2002. On calculating sterility in thermal preservation methods: application of the Weibull frequency distribution model. International Journal of Food Microbiology 72:107-113.

Manso MC, Oliveira FAR, Oliveira JC, Frías JM. 2001. Modelling ascorbic acid thermal degradation and browning in orange juice under aerobic conditions. International Journal of Food Science \& Technology 36:303-312.

Mattick LR, Moyer JC. 1983. Composition of apple juice. Journal: Association of Official Analytical Chemists 66:1251-1255.

Mayer VW, Legator MS. 1969. Production of petite mutants of Saccharomyces cerevisiae by patulin. Journal of Agricultural and Food Chemistry 13:454-456.

Moake MM, Padilla-Zakour OI, Worobo RW. 2005. Comprehensive review of patulin control methods in foods. Comprehensive Reviews in Food Science and Food Safety 4:8-21.

Morales H, Marín S, Ramos AJ, Sanchis V. 2010. Influence of post-harvest technologies applied during cold storage of apples in Penicillium expansum growth and patulin accumulation: A review. Food Control 21:953-962.

Odriozola-Serrano I, Soliva-Fortuny R, Martin-Belloso O. 2009. Influence of storage temperature on the kinetics of the changes in anthocyanins, vitamin $\mathrm{C}$, and antioxidant capacity in fresh-cut strawberries stored under high-oxygen atmospheres. Journal of Food Science 74(2):C184-C191. 
Oms-Oliu G, Odriozola-Serrano I, Soliva-Fortuny, R, Martín-Belloso O. 2009.Use of Weibull distribution for describing kinetics of antioxidant potential changes in fresh-cut watermelon. Journal of Food Engineering, 95:99-105.

Paster N, Huppert D, Barkai-Golan R. 1995. Production of patulin by different strains of Penicillium expansum in pear and apple cultivars stored at different temperatures and modified atmospheres. Food Additives and Contaminants 12:51-58.

Paucod JC. 1990. Immunotoxicity testing of mycotoxins-T-2 and patulin on BALB/C mice. Acta Microbiologica Hungarica 37:331-339.

Sharma RP. 1993. Immunotoxicity of mycotoxins. Journal of Dairy Science 76:892-897.

Taniwaki MH. 1992. Migration of patulin in apples. Journal of Food Protection 55:902-904.

Tiwari BK, O' Donnell CP, Muthukumarappan K, Cullen PJ. 2009. Ascorbic acid degradation kinetics of sonicated orange juice during storage and comparison with thermally pasteurised juice. Food Science and Technology 42:700-704.

Van Boekel Martinus AJS. 2002. On the use of the Weibull model to describe thermal inactivation of microbial vegetative cells. International Journal of Food Microbiology 74:139-159.

Villota R, Hawkes JG. 2007. Reaction kinetics in food systems. In: Handbook of Food Engineering.

Zheng H, Lu H. 2011. Use of kinetic, Weibull and PLSR models to predict the retention of ascorbic acid, total phenols and antioxidant activity during storage of pasteurized pineapple juice. Food Science and Technology 44:1273-1281. 
Table 1. Fit of the zero-order model for the degradation of patulin $\left(\mathrm{C}_{0}=6.40 \mu \mathrm{M}\right)$ without added ascorbic acid at $25,35,45,55,65$, and $85^{\circ} \mathrm{C}$.

\begin{tabular}{|c|c|c|c|c|c|c|}
\hline $\begin{array}{c}\text { Kinetic } \\
\text { model }\end{array}$ & & Kinetic constant & & Stati & ical data & \\
\hline \multirow[t]{7}{*}{$\begin{array}{c}\text { Zero } \\
\text { order }\end{array}$} & $\mathrm{T}\left({ }^{\circ} \mathrm{C}\right)$ & $\begin{array}{l}\mathbf{k}_{\mathbf{0}}(\mathbf{S D})^{1} \\
\left(\mathbf{M} \cdot \mathbf{h} \mathbf{r}^{-\mathbf{1}}\right)\end{array}$ & $\mathbf{R}^{2}$ & $\begin{array}{c}\text { SD } \\
\text { residuals } \\
(\text { Sy.x }) \\
\end{array}$ & $\begin{array}{l}\text { Runs test } \\
\text { (p-value) }\end{array}$ & $\begin{array}{c}\text { Dev. from } \\
\text { model }^{2}\end{array}$ \\
\hline & 25 & $0.0003(0.00002)$ & 0.959 & 0.0029 & 0.6457 & NS \\
\hline & 35 & $0.0005(0.00002)$ & 0.966 & 0.0044 & 0.4126 & NS \\
\hline & 45 & $0.0009(0.00003)$ & 0.987 & 0.0047 & 0.2867 & NS \\
\hline & 55 & $0.0018(0.00007)$ & 0.989 & 0.0092 & 0.0775 & NS \\
\hline & 65 & $0.0030(0.00120)$ & 0.967 & 0.0216 & 0.1212 & NS \\
\hline & 85 & $0.0157(0.00084)$ & 0.984 & 0.0341 & 0.0714 & NS \\
\hline
\end{tabular}

${ }^{1}$ Each value represents the average of three determinations. Standard deviations (SD) are shown in parentheses.

${ }^{2} \mathrm{~S}$ and NS denote that deviation of the fit of the models to the data is significant or not significant, respectively $(\alpha=0.05)$. 
Table 2. Comparison of the fit of zero, first, and second-order models to experimental data for the degradation of patulin $\left(\mathrm{C}_{0}=6.40 \mu \mathrm{M}\right)$ with added ascorbic acid $\left(\mathrm{C}_{0}=1.25 \mathrm{mM}\right)$ at $25,35,45,55$, 65 , or $85^{\circ} \mathrm{C}$.

\section{Kinetic}

Model

Kinetic constants

Statistical data

\begin{tabular}{|c|c|c|c|c|c|c|}
\hline \multirow[t]{7}{*}{$\begin{array}{l}\text { Zero- } \\
\text { order }\end{array}$} & $\mathrm{T}\left({ }^{\mathbf{0}} \mathrm{C}\right)$ & $\begin{array}{l}\mathbf{k}_{\mathbf{0}}(\mathbf{S D})^{1} \\
\left(\mathbf{M} \cdot \mathbf{h} \mathbf{r}^{-1}\right) \\
\end{array}$ & $\mathbf{R}^{2}$ & $\begin{array}{c}\text { SD } \\
\text { residuals } \\
(\mathbf{S y . x}) \\
\end{array}$ & $\begin{array}{c}\text { Runs test } \\
\text { (p-value) }\end{array}$ & $\begin{array}{c}\text { Dev. from } \\
\text { model }^{2}\end{array}$ \\
\hline & 25 & $0.0024(0.0003)$ & 0.772 & 0.0600 & 0.0009 & $\mathrm{~S}$ \\
\hline & 35 & $0.0031(0.0003)$ & 0.858 & 0.0567 & 0.0022 & $\mathrm{~S}$ \\
\hline & 45 & $0.0039(0.0005)$ & 0.780 & 0.0889 & 0.0009 & $\mathrm{~S}$ \\
\hline & 55 & $0.0042(0.0006)$ & 0.736 & 0.1102 & 0.0009 & $\mathrm{~S}$ \\
\hline & 65 & $0.0510(0.0007)$ & 0.725 & 0.1105 & 0.0002 & $\mathrm{~S}$ \\
\hline & 85 & $0.0138(0.0037)$ & 0.633 & 0.1772 & 0.0833 & NS \\
\hline \multirow[t]{7}{*}{$\begin{array}{l}\text { First- } \\
\text { order }\end{array}$} & $\mathrm{T}\left({ }^{0} \mathrm{C}\right)$ & $\begin{array}{c}\mathbf{k}_{1}(\mathrm{SD}) \\
\left(\mathbf{h r}^{-1}\right) \\
\end{array}$ & $\mathbf{R}^{2}$ & $\begin{array}{c}\text { SD } \\
\text { residuals } \\
(\mathbf{S y . x}) \\
\end{array}$ & $\begin{array}{l}\text { Runs test } \\
\text { (p-value) }\end{array}$ & $\begin{array}{c}\text { Dev. from } \\
\text { model }\end{array}$ \\
\hline & 25 & $0.0031(0.0004)$ & 0.824 & 0.0676 & 0.0009 & $\mathrm{~S}$ \\
\hline & 35 & $0.0046(0.0003)$ & 0.920 & 0.0602 & 0.0022 & $\mathrm{~S}$ \\
\hline & 45 & $0.0069(0.0006)$ & 0.898 & 0.1000 & 0.0014 & $\mathrm{~S}$ \\
\hline & 55 & $0.0083(0.0008)$ & 0.879 & 0.1340 & 0.0014 & $\mathrm{~S}$ \\
\hline & 65 & $0.0116(0.0009)$ & 0.886 & 0.1457 & 0.0002 & $\mathrm{~S}$ \\
\hline & 85 & $0.0453(0.0048)$ & 0.918 & 0.2274 & 0.0476 & $\mathrm{~S}$ \\
\hline \multirow[t]{7}{*}{$\begin{array}{l}\text { Second- } \\
\text { order }\end{array}$} & $\mathrm{T}\left({ }^{0} \mathrm{C}\right)$ & $\begin{array}{c}k_{2}(S D) \\
\left(M^{-1} \cdot h r^{-1}\right)\end{array}$ & $\mathbf{R}^{2}$ & $\begin{array}{c}\text { SD } \\
\text { residuals } \\
(\mathbf{S y . x})\end{array}$ & $\begin{array}{l}\text { Runs test } \\
\text { (p-value) }\end{array}$ & $\begin{array}{c}\text { Dev. from } \\
\text { model }\end{array}$ \\
\hline & 25 & $0.0042(0.0004)$ & 0.871 & 0.0757 & 0.0009 & $\mathrm{~S}$ \\
\hline & 35 & $0.0069(0.0003)$ & 0.961 & 0.062 & 0.1421 & NS \\
\hline & 45 & $0.0130(0.0005)$ & 0.974 & 0.092 & 0.0014 & $\mathrm{~S}$ \\
\hline & 55 & $0.0179(0.0008)$ & 0.971 & 0.1345 & 0.0357 & $\mathrm{~S}$ \\
\hline & 65 & $0.0296(0.0011)$ & 0.974 & 0.1677 & 0.0011 & $\mathrm{~S}$ \\
\hline & 85 & $0.2087(0.0160)$ & 0.956 & 0.7526 & 0.1667 & NS \\
\hline
\end{tabular}

${ }^{1}$ Each value represents the average of three determinations. Standard deviations (SD) are shown in parentheses.

${ }^{2} \mathrm{~S}$ and NS denote that deviation of the fit of the models to the data is significant or not significant, respectively $(\alpha=0.05)$ 
Table 3. Comparison of the fit of the Weibull and simplified Weibull $(n=0.453)$ model to experimental data for the degradation of patulin $\left(\mathrm{C}_{0}=6.40 \mu \mathrm{M}\right)$ with added ascorbic acid $\left(\mathrm{C}_{0}=1.25 \mathrm{mM}\right)$ at $25,35,45,55,65$, or $85^{\circ} \mathrm{C}$.

Kinetic

Model

Kinetic constants

Statistical data

\begin{tabular}{|c|c|c|c|c|c|c|c|}
\hline \multirow[t]{7}{*}{ Weibull } & $\mathrm{T}\left({ }^{0} \mathrm{C}\right)$ & $\begin{array}{c}\mathbf{b}\left(\mathbf{h r} \mathbf{r}^{-\mathbf{n}}\right) \\
(\mathbf{S D})^{1}\end{array}$ & $\begin{array}{c}\mathbf{n} \\
(\mathbf{S D}) \\
\end{array}$ & $\mathbf{R}^{2}$ & $\begin{array}{c}\text { SD } \\
\text { residuals } \\
(\text { Sy.x }) \\
\end{array}$ & $\begin{array}{l}\text { Runs test } \\
\text { (p-value) }\end{array}$ & $\begin{array}{c}\text { Dev. from } \\
\text { model }^{2}\end{array}$ \\
\hline & 25 & $\begin{array}{c}0.056 \\
(0.0082)\end{array}$ & $\begin{array}{c}0.458 \\
(0.0151)\end{array}$ & 0.993 & 0.0108 & 0.6224 & NS \\
\hline & 35 & $\begin{array}{c}(0.065 \\
(0.0041)\end{array}$ & $\begin{array}{c}0.478 \\
(0.0190)\end{array}$ & 0.988 & 0.0165 & 0.4211 & NS \\
\hline & 45 & $\begin{array}{c}0.103 \\
(0.0076)\end{array}$ & $\begin{array}{c}0.475 \\
(0.0132)\end{array}$ & 0.995 & 0.0127 & 0.8059 & NS \\
\hline & 55 & $\begin{array}{c}0.125 \\
(0.0066)\end{array}$ & $\begin{array}{c}0.478 \\
(0.0154)\end{array}$ & 0.994 & 0.0165 & 0.6224 & NS \\
\hline & 65 & $\begin{array}{c}0.236 \\
(0.0320)\end{array}$ & $\begin{array}{c}0.397 \\
(0.0116)\end{array}$ & 0.994 & 0.0163 & 0.5095 & NS \\
\hline & 85 & $\begin{array}{c}0.442 \\
(0.0130)\end{array}$ & $\begin{array}{c}0.431 \\
(0.0120)\end{array}$ & 0.999 & 0.0111 & 0.2619 & NS \\
\hline \multirow[t]{7}{*}{$\begin{array}{c}\text { Simplified } \\
\text { Weibull }\end{array}$} & $\mathrm{T}\left({ }^{0} \mathrm{C}\right)$ & $\begin{array}{c}\text { b }\left(\mathbf{h r} \mathbf{r}^{-0.453}\right) \\
(\mathrm{SD})\end{array}$ & $\mathbf{n}$ & $\mathbf{R}^{2}$ & $\begin{array}{c}\text { SD } \\
\text { residuals } \\
(\text { Sy.x }) \\
\end{array}$ & $\begin{array}{l}\text { Runs test } \\
\text { (p-value) }\end{array}$ & $\begin{array}{c}\text { Dev. from } \\
\text { model } \\
\end{array}$ \\
\hline & 25 & $\begin{array}{l}0.06234 \\
(0.0007)\end{array}$ & 0.453 & 0.992 & 0.0109 & 0.6224 & NS \\
\hline & 35 & $\begin{array}{l}0.07645 \\
(0.0011)\end{array}$ & 0.453 & 0.985 & 0.0179 & 0.3621 & NS \\
\hline & 45 & $\begin{array}{c}0.1182 \\
(0.0014)\end{array}$ & 0.453 & 0.993 & 0.0152 & 0.4266 & NS \\
\hline & 55 & $\begin{array}{c}0.1445 \\
(0.0021)\end{array}$ & 0.453 & 0.991 & 0.0193 & 0.1084 & NS \\
\hline & 65 & $\begin{array}{c}0.2019 \\
(0.0029)\end{array}$ & 0.453 & 0.990 & 0.0210 & 0.0882 & NS \\
\hline & 85 & $\begin{array}{c}0.4327 \\
(0.0049)\end{array}$ & 0.453 & 0.999 & 0.0108 & 0.2619 & NS \\
\hline
\end{tabular}

${ }^{1}$ Each value represents the average of three determinations. Standard deviations (SD) are shown in parentheses.

${ }^{2} \mathrm{~S}$ and NS denote that deviation of the fit of the models to the data is significant or not significant, respectively $(\alpha=0.05)$ 
Figure 1: Degradation of patulin $\left(\mathrm{C}_{0}=6.40 \mu \mathrm{M}\right)$ without added AA at $(\bullet), 35(\boldsymbol{\square}), 45(\boldsymbol{\Delta})$, $55(\nabla), 65(\diamond)$, or $85{ }^{\circ} \mathrm{C}(\circ)$ and the fit of the zero-order kinetic model to the experimental data. Each point represents the average of three replicate experiments.

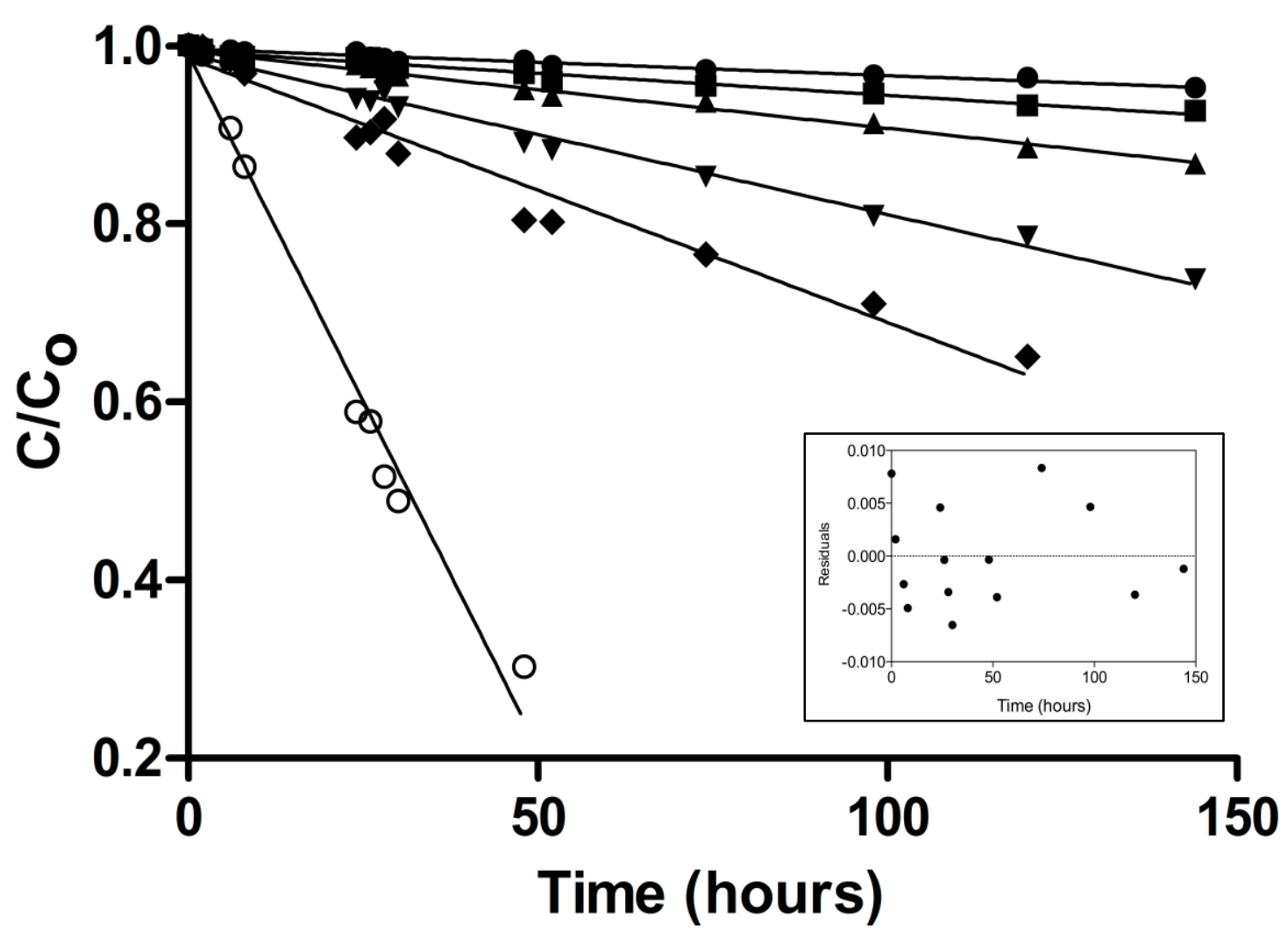


Figure 2: Degradation of patulin $\left(\mathrm{C}_{0}=6.40 \mu \mathrm{M}\right)$ with added ascorbic acid $(1.25 \mathrm{mM})$ at $(\bullet), 35(\boldsymbol{\bullet}), 45(\boldsymbol{\Delta}), 55(\boldsymbol{\nabla}), 65(\bullet)$, or $85{ }^{\circ} \mathrm{C}(\mathrm{\circ})$ and the fit of the (a) zero-order, (b) firstorder, and (c) second-order kinetic model to the experimental data. Each point represents the average of three replicate experiments.

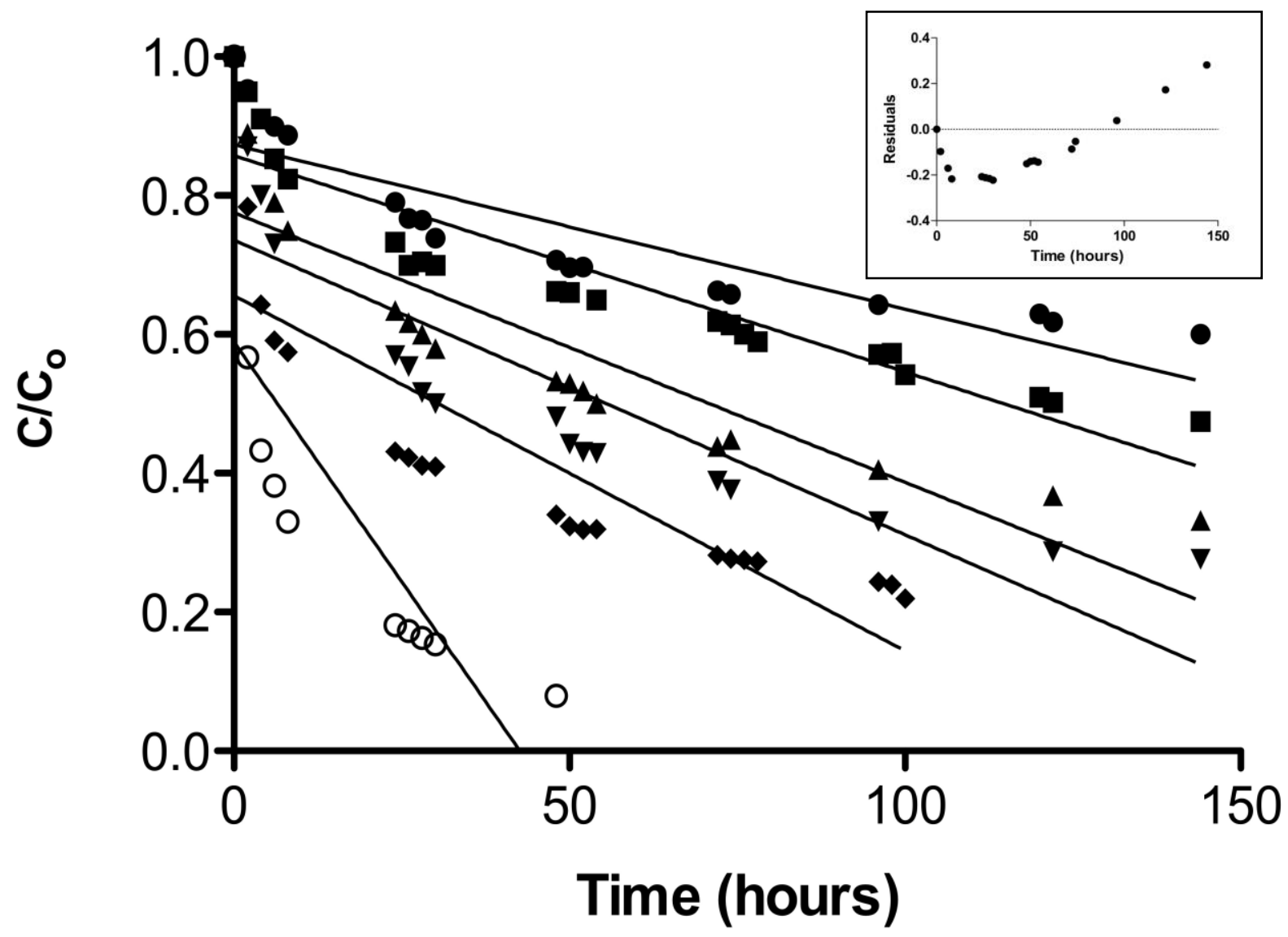




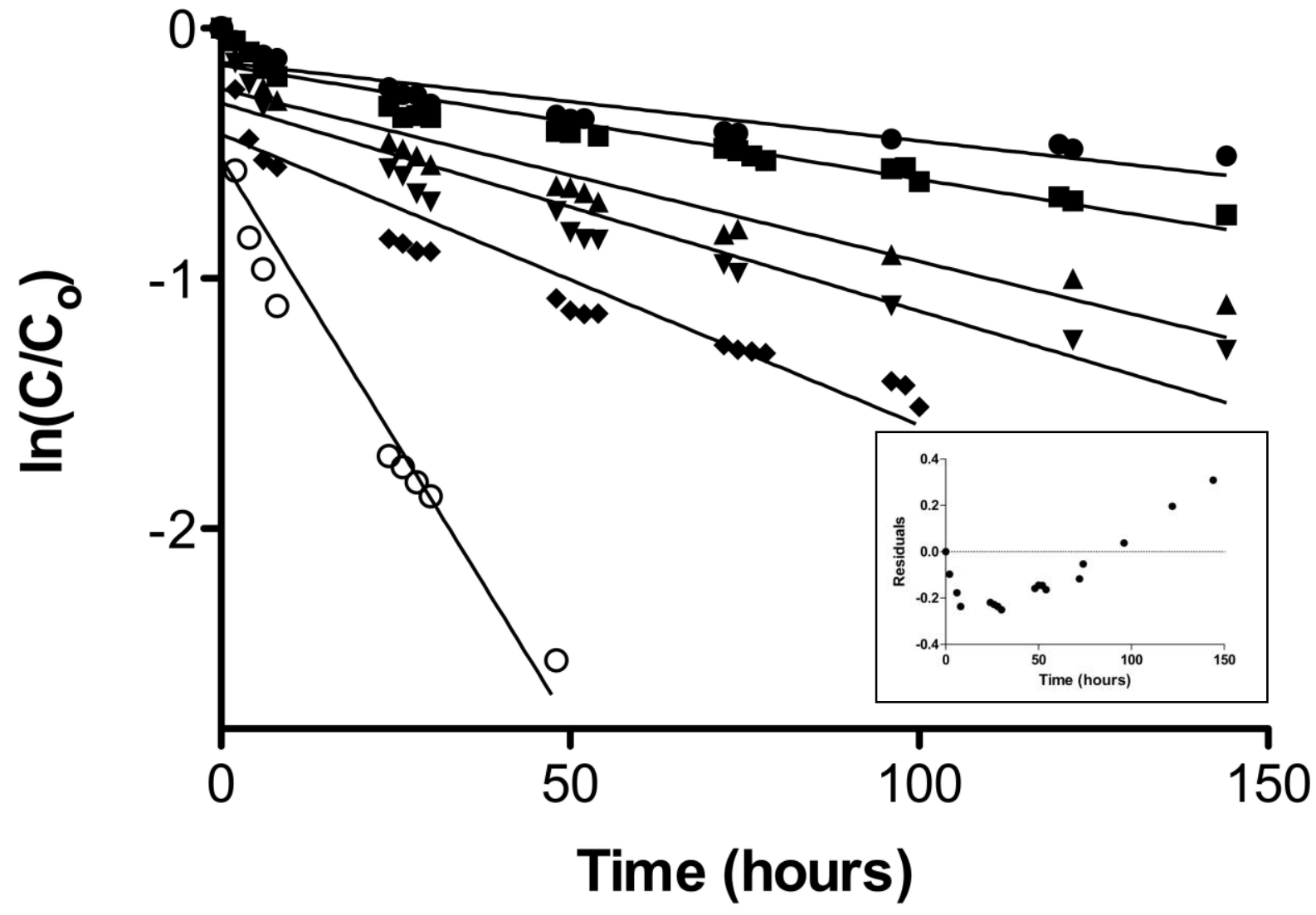


2(c)

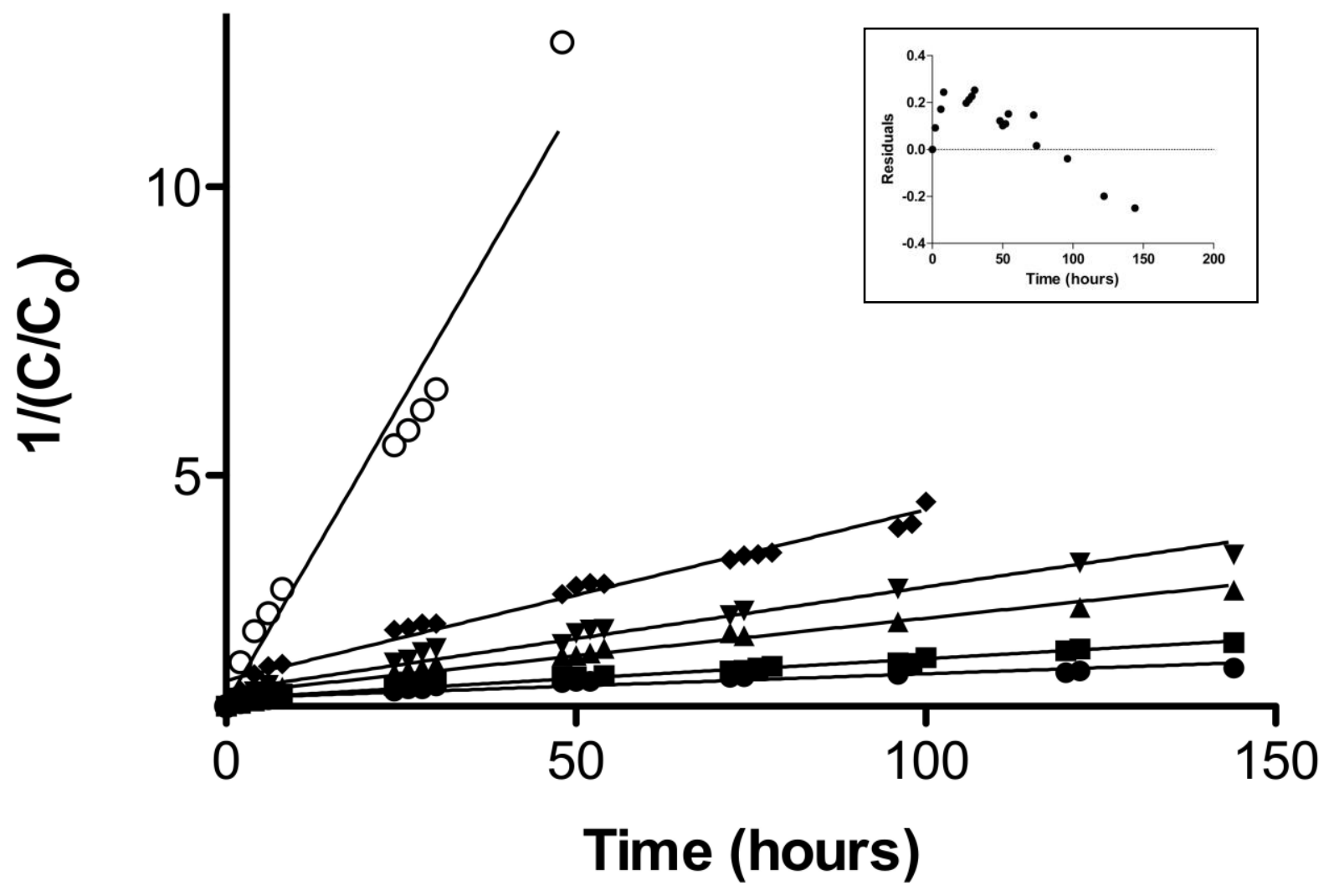


Figure 3: Degradation of patulin $\left(\mathrm{C}_{\mathrm{o}}=6.40 \mu \mathrm{M}\right)$ with added ascorbic acid $\left(\mathrm{C}_{\mathrm{o}}=1.25 \mathrm{mM}\right)$ at $(\bullet), 35(\bullet), 45(\boldsymbol{\Delta}), 55(\boldsymbol{\nabla}), 65(\bullet)$, or $85{ }^{\circ} \mathrm{C}(\mathrm{\circ})$ and the fit of the (a) Weibull and (b) simplified Weibull $(n=0.453)$ kinetic model to the experimental data. Each point represents the average of three replicate experiments.

3(a)

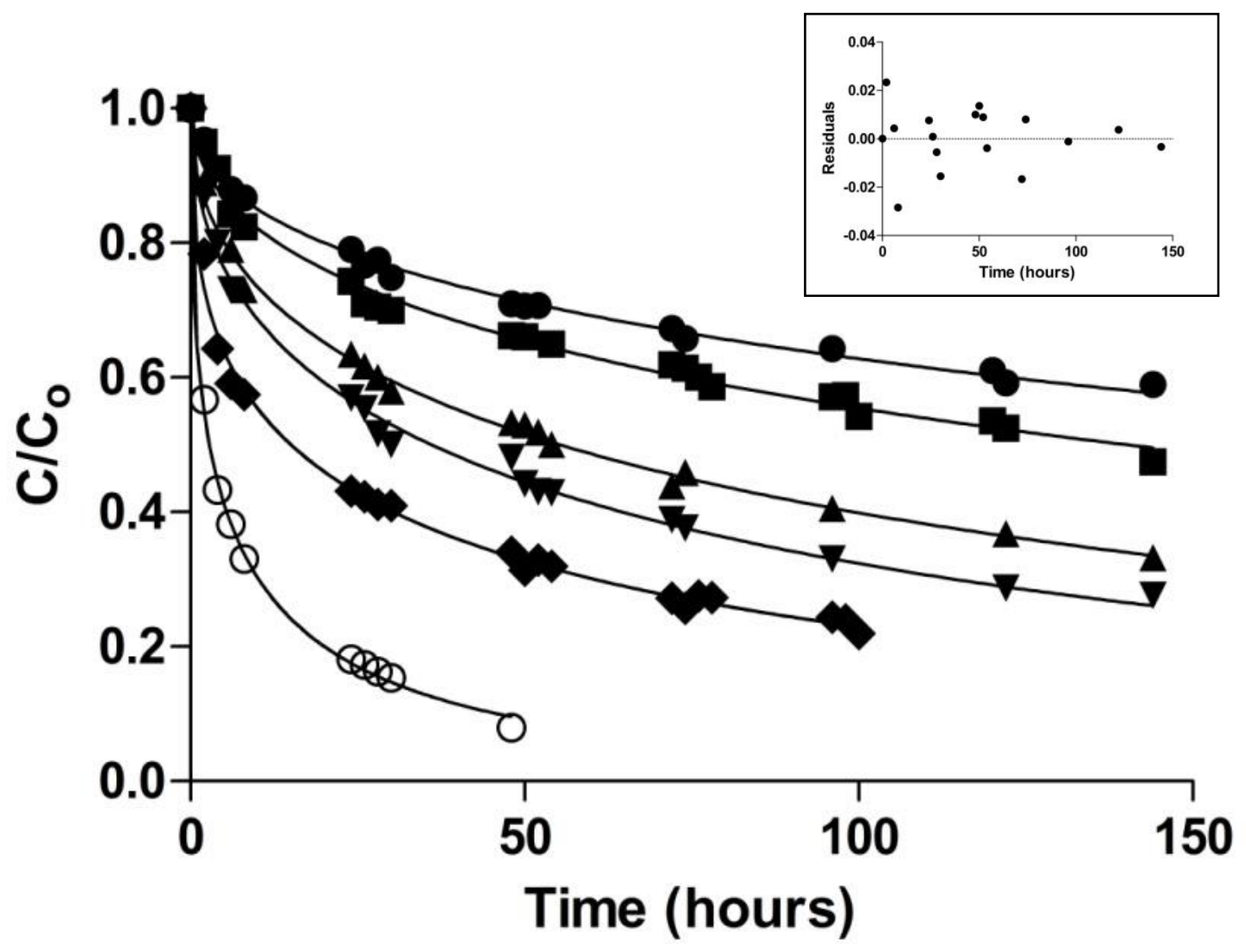


3(b)

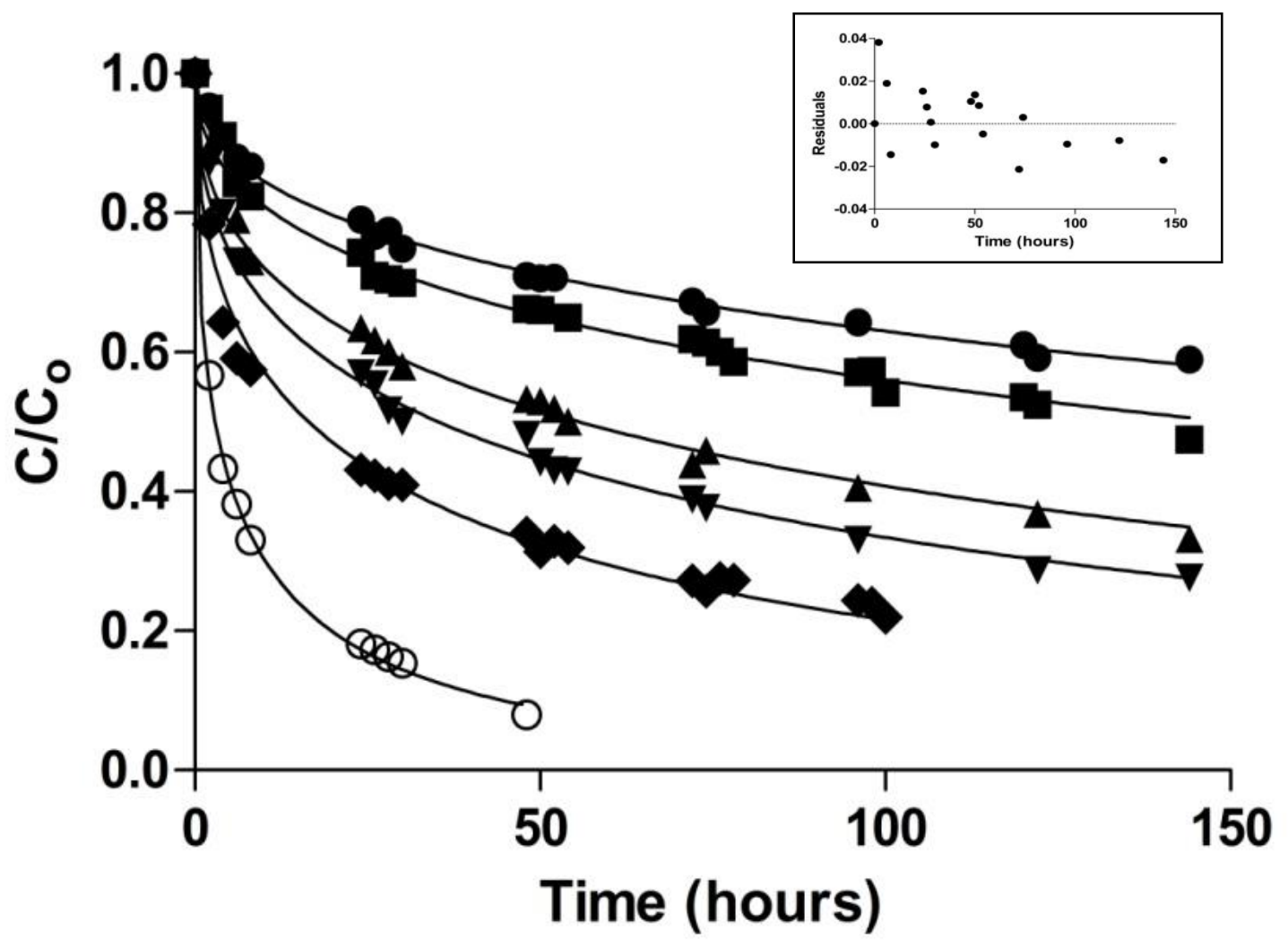


Figure 4: Arrhenius plot for the degradation of patulin $\left(\mathrm{C}_{\mathrm{o}}=6.40 \mu \mathrm{M}\right)$ between 25 and 85 ${ }^{\circ} \mathrm{C}$ without $(\bullet)$ or with $(\boldsymbol{\Delta})$ added ascorbic acid $(1.25 \mathrm{mM})$. Each point represents the average of 3 determinations \pm the standard deviation

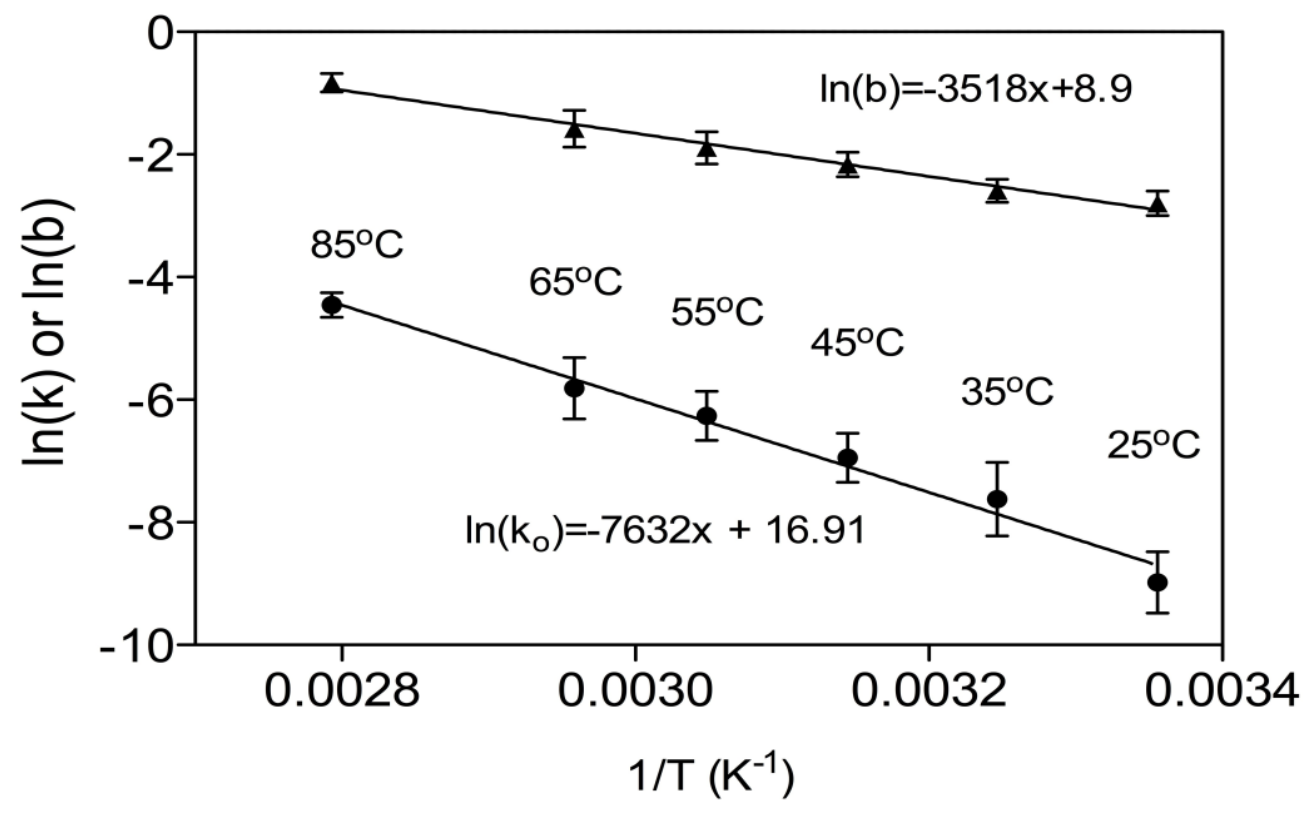

